\title{
Modifiable Cardiovascular Disease Risk Factors among Indigenous Populations
}

\author{
Adam A. Lucero, ${ }^{1}$ Danielle M. Lambrick, ${ }^{2}$ James A. Faulkner, ${ }^{1}$ Simon Fryer, ${ }^{3}$ \\ Michael A. Tarrant, ${ }^{4}$ Melanie Poudevigne, ${ }^{5}$ Michelle A. Williams, ${ }^{6}$ and Lee Stoner ${ }^{1}$ \\ ${ }^{1}$ School of Sport and Exercise, Private Bag 756, Massey University, Wellington 6140, New Zealand \\ ${ }^{2}$ Institute of Food Nutrition and Human Health, Massey University, Wellington 6140, New Zealand \\ ${ }^{3}$ Faculty of Applied Sciences, University of Gloucestershire, The Park, Cheltenham, Gloucestershire GL50 2RH, UK \\ ${ }^{4}$ Warnell School of Forestry, University of Georgia, Athens, GA 30602, USA \\ ${ }^{5}$ Health \& Fitness Management Program, Office of the Dean, Clayton State University, Morrow, GA 30260, USA \\ ${ }^{6}$ Department of Epidemiology, Harvard School of Public Health, Boston, MA 02115, USA
}

Correspondence should be addressed to Adam A. Lucero; a.lucero@massey.ac.nz

Received 12 June 2013; Revised 7 October 2013; Accepted 9 October 2013; Published 6 February 2014

Academic Editor: John Iskander

Copyright (c) 2014 Adam A. Lucero et al. This is an open access article distributed under the Creative Commons Attribution License, which permits unrestricted use, distribution, and reproduction in any medium, provided the original work is properly cited.

\begin{abstract}
Objective. To identify modifiable cardio-metabolic and lifestyle risk factors among indigenous populations from Australia (Aboriginal Australians/Torres Strait Islanders), New Zealand (Māori), and the United States (American Indians and Alaska Natives) that contribute to cardiovascular disease (CVD). Methods. National health surveys were identified where available. Electronic databases identified sources for filling missing data. The most relevant data were identified, organized, and synthesized. Results. Compared to their non-indigenous counterparts, indigenous populations exhibit lower life expectancies and a greater prevalence of CVD. All indigenous populations have higher rates of obesity and diabetes, hypertension is greater for Māori and Aboriginal Australians, and high cholesterol is greater only among American Indians/Alaska Natives. In turn, all indigenous groups exhibit higher rates of smoking and dangerous alcohol behaviour as well as consuming less fruits and vegetables. Aboriginal Australians and American Indians/Alaska Natives also exhibit greater rates of sedentary behaviour. Conclusion. Indigenous groups from Australia, New Zealand, and the United States have a lower life expectancy then their respective non-indigenous counterparts. A higher prevalence of CVD is a major driving force behind this discrepancy. A cluster of modifiable cardio-metabolic risk factors precede CVD, which, in turn, is linked to modifiable lifestyle risk factors.
\end{abstract}

\section{Introduction}

Cardiovascular disease (CVD) is considered the primary influencing factor in the life expectancy discrepancy between indigenous and nonindigenous groups in many countries [1]. Preceding CVD, many groups exhibit a cluster of cardiometabolic risk factors, which, in turn, is linked with a number of modifiable lifestyle risk factors (Figure 1). Multiple studies have revealed that modifiable risk factors are responsible for a large number of premature deaths due to CVD $[2,3]$. Recently, it was reported that the single largest risk factor for cardiovascular mortality in the US was high blood pressure, directly responsible for $45 \%$ of all
CVD deaths, closely followed by obesity, physical inactivity, high cholesterol, and smoking [2]. Fortunately, many of these metabolic and lifestyle risk factors are modifiable and relatively simple to monitor.

The current review will focus on known modifiable cardio-metabolic (overweight obesity, diabetes, high cholesterol, and high blood pressure; see Table 1) and common lifestyle (physical inactivity, poor nutrition, dangerous alcohol behaviour, and cigarette smoking; see Table 2) risk factors among indigenous populations from Australia, New Zealand, and the United States. Comparisons will be made with nonindigenous groups, and discussion will focus on the association of lifestyle factors and cardiovascular-metabolic 
TABLE 1: Prevalence of cardio-metabolic risk factors among adults.

\begin{tabular}{|c|c|c|c|c|c|c|c|c|c|c|c|}
\hline \multirow{2}{*}{ Group } & \multicolumn{2}{|c|}{ Population } & \multirow{2}{*}{$\begin{array}{l}\text { Life expect. } \\
\quad \text { yrs }\end{array}$} & \multicolumn{2}{|c|}{ CVD } & \multicolumn{2}{|c|}{ Body weight } & \multirow[b]{2}{*}{$\begin{array}{c}\text { Diabetes } \\
\%\end{array}$} & \multirow[b]{2}{*}{$\begin{array}{c}\text { High cholest. } \\
\%\end{array}$} & \multirow{2}{*}{$\begin{array}{c}\text { HT } \\
\%\end{array}$} & \multirow{2}{*}{ References } \\
\hline & million & $\%$ & & $\begin{array}{c}\text { Prev. } \\
\% \\
\end{array}$ & $\begin{array}{c}\text { Mortality } \\
\% \\
\end{array}$ & $\begin{array}{c}\text { Over } \\
\% \\
\end{array}$ & $\begin{array}{c}\text { Obese } \\
\% \\
\end{array}$ & & & & \\
\hline $\mathrm{AU}$ & 20.8 & 100 & 81 & 17 & 9 & 29 & 22 & 4 & 7 & 10 & \multirow{3}{*}[13,114,115]{} \\
\hline White AU & 20.3 & 98 & 81 & 17 & 9 & 29 & 22 & 4 & 7 & 10 & \\
\hline Indigenous AU & 0.52 & 2.5 & 62 & 22 & 27 & 35 & 27 & 12 & 6 & 15 & \\
\hline $\mathrm{NZ}$ & 4.03 & 100 & 80 & 5 & 31 & 36 & 27 & 5 & 8 & 14 & \multirow{3}{*}{$\begin{array}{c}{[6,14,16,26} \\
116]\end{array}$} \\
\hline White NZ & 2.61 & 68 & 81 & 4 & 32 & 32 & 24 & 4 & 8 & 13 & \\
\hline Indigenous NZ & 0.57 & 15 & 73 & 7 & 32 & 32 & 42 & 8 & 9 & 17 & \\
\hline U.S. & 309 & 100 & 78 & 21 & 34 & 33 & 33 & 8 & 16 & 34 & \multirow{3}{*}{$\begin{array}{c}{[7,17,19,54,} \\
107]\end{array}$} \\
\hline White U.S. & 309 & 100 & 78 & 21 & 34 & 33 & 31 & 6 & 17 & 33 & \\
\hline Indigenous U.S. & 5.22 & 1.7 & 75 & 23 & 25 & 28 & 42 & 15 & 31 & 30 & \\
\hline
\end{tabular}

CVD: cardiovascular disease; HT: Hypertension.

Notes: a body mass index (BMI) $\geq 25.0 \mathrm{~kg} / \mathrm{m}^{2}$ is considered overweight, $\geq 30.0 \mathrm{~kg} / \mathrm{m}^{2}$ is considered obese.

AU: CVD, cholesterol, diabetes (includes high sugar levels), and body weight data are self-reported and age-adjusted for adults $\geq 18$ yrs [13].

NZ: diabetes = physician diagnosed; high cholesterol: individuals medicated for high total cholesterol [26]; HT = currently taking prescribed blood pressure medication [26]; HT, cholesterol, diabetes, and body weight data are for adults aged $\geq 15$ [26]; CVD data are age-adjusted for adults $\geq 18$ [14, 16].

US: diabetes $=$ physician diagnosed; high cholesterol $=\geq 240 \mathrm{mg} / \mathrm{dL}$ [17]; HT = defined as SBP $\geq 140 \mathrm{mmHg}$ and/or DBP $\geq 90 \mathrm{mmHg}$, use of antihypertensive medication, or physician diagnosed [17]; CVD, hypertension, diabetes, and body weight data are age-adjusted for adults $\geq 20$ [17].

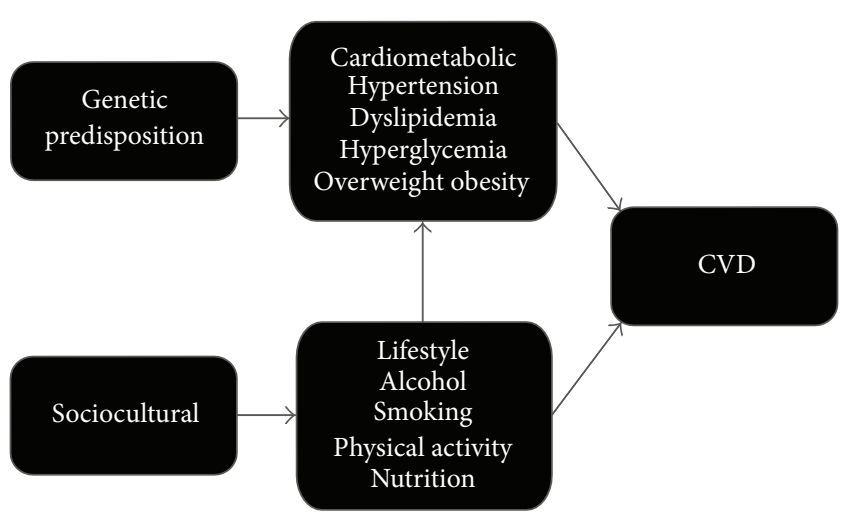

Figure 1: Causation pathway for cardiovascular disease (CVD) [4].

conditions. Recommendations will be provided for measuring and tracking each of these risk factors.

\section{Methods}

2.1. Data Sources. Electronic databases included PubMed, Medline, and Google Scholar. All titles were exported to Endnote and checked for duplicates.

2.2. Study Inclusion and Exclusion Criteria. National health surveys were identified where available. Electronic databases identified sources for filling missing data. Criteria for inclusion of articles included (a) published in a peer-reviewed English-language journal or government report; (b) contained data from nonindigenous cohorts for use as a comparison group; (c) cited in health science, nursing, medical, or exercise science literature. The largest sample studies containing data for CVD prevalence and mortality published between 2002 and July 2012 were selected to compare data of CVD and lifestyle risk factors and conditions (Tables 1 and 2).

2.3. Data Extraction and Data Synthesis. Search terms included Aboriginal Australians, Māori, American Indians/Alaska Natives, indigenous, cardiovascular disease, heart disease, overweight, obesity, diabetes, cholesterol, blood pressure, hypertension, alcohol, physical activity, exercise, nutrition, cigarette smoking, and tobacco.

\section{Demographics}

3.1. Australia. For the purpose of this paper, the term indigenous Australian refers to those of Aboriginal origin and Torres Strait Islanders. The indigenous population is estimated to be $2.5 \%$ of the total Australian population, approximately $90 \%$ of which self identify as Aboriginal, $6 \%$ as Torres Strait Islander, and 4\% both mixed [5]. The indigenous population is relatively young, with a median age of 20.5 years compared to 36.6 years for the nonindigenous population [5]. Around $26 \%$ of indigenous people live in remote areas, compared with only $2 \%$ nonindigenous peoples [5], and many continue to maintain a strong connection to their traditional culture, language, and lands.

3.2. New Zealand. For the purpose of this paper, the term indigenous New Zealander encompasses those of Māori descent. Māori people comprise $15 \%$ of the total population [6], with the predominance $(84.4 \%)$ residing in urban areas [6]. The Mãori population has a median age of 22.7 years compared to 35.9 years for the nonindigenous population [6]. Māori culture continues to be an important thread of New 
TABLE 2: Prevalence of modifiable lifestyle risk factors.

\begin{tabular}{|c|c|c|c|c|c|c|c|c|}
\hline \multirow{2}{*}{ Group } & \multicolumn{2}{|c|}{ Activity behaviour } & \multicolumn{2}{|c|}{ Nutrition } & \multicolumn{2}{|c|}{ Alcohol behaviour } & \multirow{2}{*}{$\begin{array}{c}\text { Smokers } \\
\%\end{array}$} & \multirow{2}{*}{ References } \\
\hline & $\begin{array}{c}\text { Sedentary } \\
\% \\
\end{array}$ & $\begin{array}{c}\text { Prescribed } \\
\% \\
\end{array}$ & $\begin{array}{c}\text { Veg. } \\
\% \geq 2 \text { day }\end{array}$ & $\begin{array}{c}\text { Fruit } \\
\% \geq 2 \text { day }\end{array}$ & $\begin{array}{c}\text { Any } \\
\%\end{array}$ & $\begin{array}{c}\text { Risky } \\
\%\end{array}$ & & \\
\hline $\mathrm{AU}$ & 33 & 33 & 78 & 52 & 83 & 14 & 21 & \\
\hline White AU & 33 & 33 & 78 & 52 & 83 & 14 & 21 & [13] \\
\hline Indigenous AU & 51 & 21 & 43 & 26 & 49 & 15 & 46 & \\
\hline New Zealand & 15 & 51 & 64 & 60 & 85 & 13 & 20 & \\
\hline White NZ & 14 & 51 & 67 & 63 & 90 & 12 & 19 & {$[26,81]$} \\
\hline Indigenous NZ & 14 & 51 & 62 & 56 & 85 & 24 & 38 & \\
\hline U.S. & 39 & 11 & \multicolumn{2}{|c|}{23} & 55 & 7 & 21 & \\
\hline White U.S. & 37 & 12 & \multicolumn{2}{|c|}{ N/A } & 60 & 8 & 22 & {$[10,17,82,107]$} \\
\hline Indigenous U.S. & 40 & 10 & \multicolumn{2}{|c|}{17} & 48 & 12 & 24 & \\
\hline
\end{tabular}

AU: sedentary activity behavior $=<50$ mins/week, moderate: $>800$ mins/week, for adults $\geq 15$ yrs [13]; risky alcohol behavior $=\geq 5$ standard drinks/day for males (or $\geq 15 /$ week) and $\geq 4$ for females (or $\geq 8 /$ week) for adults aged $\geq 18$ yrs [13]; smoker: any type of tobacco consumption [13]; smoking, activity and nutrition data are age-adjusted for adults $\geq 18$ yrs [13].

NZ: prescribed activity behavior $=$ recommended $\geq 30 \mathrm{mins} /$ day most days or at least $150 \mathrm{mins} /$ week, sedentary activity behavior $=<30 \mathrm{mins} /$ week [26]; risky alcohol behavior $=$ weekly binge ( $\geq 6$ standard drinks on one occasion for males and $\geq 4$ for females) drinking, age-adjusted for adults aged 16-64 [81]; smoker $=$ cigarette smoking [26]; vegetable $=\geq 3$ servings/day [26]; smoking, activity and nutrition date are age-adjusted for adults aged 16-64 [26].

US: prescribed activity behavior $=\geq 30 \mathrm{mins} /$ day most days or at least $150 \mathrm{mins} /$ week (self-reported, $\geq 18$ yrs), age-adjusted for adults aged $\geq 18$ yrs [107]; nutrition $=\geq 5$ servings/day of vegetables/fruit, age-adjusted for adults aged $\geq 18$ yrs [10]; risky alcohol behaviour $=\geq 5$ standard drinks/day on $\geq 5$ days in past 30 days [82]; smoking = cigarette smoking, age-adjusted for adults aged $\geq 20$ [107].

Zealand society with $23.7 \%$ of Māori being able to hold a conversation in te Reo Māori [6].

3.3. United States. For the purpose of this paper, the term indigenous for a person from the United States encompasses American Indians and Alaska Natives. There are approximately 5.2 million reported indigenous Americans in the United States, representing $1.7 \%$ of the population, including those of more than one race [7]. The indigenous population is younger than the nonindigenous population (30.3 years compared to (cf.) 36.6 years, resp., [8]), and is varied with 566 federally recognized tribes [9]. These tribal groups often have different histories, unique languages, and varied cultural traditions, reside in numerous geographic regions, and show various degrees of societal assimilation [10]. In 2010, the majority $(78 \%)$ of indigenous Americans lived outside of native reservation areas [11].

3.4. Cardiovascular Disease. CVD covers all diseases and conditions of the heart and blood vessels. Coronary heart disease (CHD), stroke, heart failure, and peripheral vascular disease contribute approximately $30 \%$ to the CVD burden in developed countries [12]. In 2001, CVD was the primary cause of death worldwide, with indigenous peoples leading the way [1].

3.4.1. Australia. CVD is the principal cause of death among all ethnic groups in Australia [13]. The 2004-05 National Aboriginal and Torres Strait Islander Health Survey (NATSIHS, the largest health survey of Indigenous Australians, [13]) found age-adjusted rates for CVD that were 30\% higher among the indigenous population (22\%) compared to the nonindigenous (17\%) population, with CVD mortality three times higher (27\% cf. 9\%, resp.). Indigenous Australians show a marked increase in the prevalence of CVD from around 35 years of age onwards, some 10 years earlier than in the nonindigenous population.

3.4.2. New Zealand. Across all ethnic groups, CVD mortality peaked between 1966 and 70, and since then, death rates have fallen by over $60 \%$ in all age and sex groups $[14,15]$. However, the decline has been slower among indigenous New Zealanders. Between 1981 and 2004, CVD mortality rates decreased by $43 \%$ among indigenous New Zealanders compared to $65 \%$ among nonindigenous New Zealanders $[14,15]$. Indigenous New Zealanders continue to have a higher prevalence of CVD compared to their nonindigenous counterparts (7\% cf. 4\%, resp., [16]). Chan et al. [16] found that CVD prevalence begins to rise after age 35 years among all age groups, but the rise in prevalence rate is greater among indigenous New Zealanders.

3.4.3. United States. Among all ethnicities, CVD accounted for $34 \%$ of all deaths in 2010 [17], 33\% of which occurred before the age of 75 years-well before the average life expectancy of 78 years. According to the National Center for Health Statistics (NCHS) [18], if all forms of major CVD were eliminated, life expectancy would rise by almost 7 years. Despite a lower life expectancy and a slightly higher prevalence of CVD among indigenous versus nonindigenous Americans (23\% cf. 21\%), CVD mortality is lower $(25 \%$ cf. 34\%) [17]. These discrepant findings may be partially explained by higher rates of mortality among indigenous Americans for tuberculosis (600\% higher), alcoholism (510\% higher), motor vehicle crashes (229\% higher), diabetes (189\% 
higher), unintentional injuries (152\% higher), homicide (61\% higher), and suicide (62\% higher) [19].

\section{Modifiable Cardiometabolic Metabolic Risk Factors}

4.1. Obesity. Excess body fat increases the risk of developing a range of health problems, including high blood pressure, diabetes mellitus, and CVD [20-22]. According to results from the Framingham Heart Study [20], age-adjusted relative risk for CVD is increased for overweight and obese men ( $21 \%$ and $46 \%$, resp.) and women (20\% and $64 \%$, resp.) when compared with normal weight individuals. Population studies, including those retrieved for the current paper, typically estimate the proportion of people that are obese by calculating an individual's body mass index (BMI). BMI is based on the assumption that the ratio between body mass and height provides an indication of body fatness; however, this often discriminates against individuals (and/or populations) that have a higher proportion of muscle mass. Alternatively, waist circumference, waist-to-height ratio, and waist-to-hip ratio (WHR) take into consideration body-fat distribution, especially central (abdominal) obesity [23]. A recent study compared the predictive power of BMI, waist circumference, waist-to-height ratio, and WHR for diabetes mellitus, hypertension, and dyslipidemia in Australian Aboriginal and Torres Strait Islander adults [24]. WHR was found to have the greatest predictive power. A WHR of $\geq 0.90$ and $\geq 0.80$, for males and, females respectively, is considered optimal. However, studies over the past two decades indicate that the rate of risk for a given WHR differs between ethnic groups; therefore these reference values should not be used to ascertain absolute risk [25].

4.1.1. Australia. After adjusting for age differences between the two populations, the 2004/05 NATSIHS [13] reported that indigenous Australians are 1.2 times more likely to be overweight/obese than nonindigenous Australians (62\% cf. $51 \%)$. In each age group, the disparity between indigenous and nonindigenous groups was greater for females than for males and was more pronounced within remote geographical areas.

4.1.2. New Zealand. The 2006/07 New Zealand National Health Survey (NZNHS) [26] reported that $36 \%$ of adults were overweight and a further $27 \%$ were obese. The obesity burden is particularly prevalent among indigenous New Zealanders, with $42 \%$ of this population being obese compared to $24 \%$ of their white counterparts [26]. However, there was no significant increase reported for either ethnic group between 2002/3 and 2006/07.

4.1.3. United States. An estimated $144,100,000$ people or $66 \%$ of the total US adult population is overweight or obese [17]. The rates of overweight/obesity are comparable between indigenous and white Americans. However, while indigenous Americans are less likely to be overweight (28\%) than white Americans (33\%) they are more likely to be obese ( $42 \%$ cf.
$31 \%$, resp.). These findings have been corroborated by other studies [10].

4.2. Diabetes. Diabetes mellitus is a group of metabolic diseases in which hyperglycaemia results from defective insulin secretion, insulin action, or both [27, 28]. There are several forms of diabetes mellitus, each with a different cause and clinical history. The two most prominent forms are type 1 and type 2 diabetes, which differ according to their underlying pathophysiology, with type 1 often attributed to an autoimmune response and type 2 often related to several lifestyle factor. type 2 diabetes accounts for $90-95 \%$ of diabetes cases and is a major risk factor for CVD [17, 2934]. A meta-analysis [34], encompassing 6,573 subjects found that type 2 diabetes resulted in greater CVD mortality risk (RR 3.42, 95\% CI: 2.23 to 5.23) than hypertension (RR 1.57, 95\% CI: 1.10 to 2.24 ) or hypercholesteremia (RR $1.49,95 \%$ CI: 1.05 to 2.10 ). In turn, diabetes is modified by lifestyle factors, including physical inactivity and poor nutrition, in addition to any genetic predisposition and the natural ageing process [35-39]. Diabetes mellitus risk can be monitored by measuring glucose tolerance or fasting blood glucose, where a fasting blood glucose of $<100 \mathrm{mg} / \mathrm{dL}$ is considered optimal [40].

4.2.1. Australia. The $2007 / 08$ Australian National Health Survey [41] reported that an estimated $4 \%$ of the total population had diagnosed diabetes. According to the 2004/05 NATSIHS [13], the age-standardized prevalence of diabetes/elevated blood glucose (i.e., prediabetes) among indigenous Australians was 3.4 times the rate of that observed in nonindigenous people ( $12 \% \mathrm{cf}$. $4 \%)$. The prevalence of diabetes among indigenous Australians increases rapidly after 35 years of age, rising from $10 \%$ at age $35-44$ years to $32 \%$ at age 55 years and over. By contrast, the prevalence increases from $2 \%$ to $12 \%$ for nonindigenous people. Prevalence rates among indigenous Australians are similar between genders, but those in remote areas are almost twice as likely to have diabetes [13].

4.2.2. New Zealand. The $2006 / 07$ NZNHS [26] reported 5\% of the total population was diagnosed with diabetes. Indigenous New Zealanders were twice as likely to be diagnosed with diabetes ( $8 \% \mathrm{cf} .4 \%$, resp.). There has been no significant change in diabetes prevalence between 1996/97 and 2006/07 for both indigenous and nonindigenous populations or for males and females [26].

4.2.3. United States. In 2006 , an estimated $17,200,000$ Americans had diagnosed diabetes, representing $8 \%$ of the adult population [17]. A further estimated 6,100,000 had undiagnosed diabetes and $29 \%$ had prediabetes with abnormal fasting glucose levels. Diabetes was once rare among indigenous Americans, but the prevalence is rising dramatically with rates almost twice as high when compared with their nonHispanic white counterparts (15\% cf. 8\%, resp.) [17]. 
4.3. Cholesterol. The two most common blood lipids are cholesterol and triglycerides. These two blood fats are carried on particles called lipoproteins, the most important of which are low density lipoprotein (LDL) and high density lipoprotein (HDL). Both carry cholesterol, but high levels of LDL cholesterol have been shown to be atherogenic [4244]. Similarly, low levels of HDL cholesterol are associated with increased CHD morbidity and mortality [45-47]. High HDL cholesterol levels conversely convey reduced risk [4548]. In population studies, serum total cholesterol is often used as a surrogate for LDL cholesterol levels; however, LDL concentrations confers more predictive value. The best way to determine the true prevalence of high cholesterol in the community is through blood samples [26]. An LDL cholesterol level $<100 \mathrm{mg} / \mathrm{dL}$ is considered optimal [49].

4.3.1. Australia. The 2004/05 NATSIHS [13] found the prevalence of high age-adjusted serum total cholesterol levels to be similar for indigenous (6\%) and nonindigenous (7\%) groups. The same report found the prevalence of high total cholesterol levels to drastically increase with age, starting at $4 \%$ for both indigenous and nonindigenous groups when aged 3544 years, rising to $18 \%$ and $20 \%$, respectively, aged 55 years or over.

4.3.2. New Zealand. The $2006 / 07$ NZNHS [26] reported that $8 \%$ of the total adult ( $\geq 15$ years) population were currently taking medication for high cholesterol. Men (8\%) were significantly more likely than women $(6 \%)$ to be taking medication for high cholesterol, when standardized for age. Age-standardized cholesterol levels are similar between indigenous and nonindigenous groups. However, the lack of differences in cholesterol between populations may be misleading as the NZNHS data only details the number of individuals on medication for high cholesterol, therefore excluding those who remain undiagnosed.

4.3.3. United States. In 2006 , an estimated $102,200,000$ people or $47 \%$ the total US adult population $(\geq 20)$ had total cholesterol levels above $\geq 200 \mathrm{mg} / \mathrm{dL}$, with an estimated $16 \%$ registering a cholesterol level $\geq 240 \mathrm{mg} / \mathrm{dL}$ [17]. The prevalence of high total cholesterol ( $\geq 240 \mathrm{mg} / \mathrm{dL}$ ) is substantially greater for indigenous Americans compared to nonindigenous Americans (31\% cf. 17\%) [17].

4.4. Hypertension. Hypertension is a major risk factor for CVD. For every $20 \mathrm{mmHg}$ systolic or $10 \mathrm{mmHg}$ diastolic increase in resting blood pressure there is a twofold increase in risk of death from ischemic heart disease or stroke [50]. Hypertension is associated with shorter overall life expectancy and earlier onset of CVD [51]. According to the WHO, hypertension is likely the leading risk factor for death worldwide [52]. In part, this is because hypertension is common and because management of hypertension is suboptimal [53]. An ideal blood pressure is one with a systolic pressure $<120 \mathrm{mmHg}$ and a diastolic pressure $<80 \mathrm{mmHg}$ [40].
4.4.1. Australia. In 2004/05, hypertension was the most commonly reported CVD condition among indigenous Australians, with prevalence rates $50 \%$ greater than for nonindigenous Australians when adjusted for age (10\% cf. 15\%, resp.) [13]. Hypertension is of particular concern to remote indigenous groups with an overall prevalence of $6 \%$ among urban dwellers versus $10 \%$ for remote dwellers. For both ethnic groups prevalence increases dramatically with age, from 12 to $43 \%$ for indigenous and $4-33 \%$ for nonindigenous groups between the ages 35-44 years and 55+ years, respectively.

4.4.2. New Zealand. In $2006 / 07$ one in seven adults (14\%) reported that they were currently taking medication for high blood pressure [26]. After adjusting for age, indigenous New Zealanders were $26 \%$ more likely to have elevated blood pressure than the general population.

4.4.3. United States. Data from the 2006 National Health and Nutrition Examination Survey (NHANES) [54] indicate that $34 \%$ of US adults over 20 years have hypertension. Rates of hypertension are slightly lower among indigenous (30\%) than nonindigenous Americans (33\%) [54].

\section{Modifiable Lifestyle Risk Factors}

5.1. Nutrition. Poor dietary habits affect multiple cardiovascular risk factors including blood pressure, cholesterol levels, glucose levels, and obesity [55-61]. A diet high in nutrientrich (vitamins, minerals, antioxidants and fibre) fruits and vegetables can reduce the risk for many leading causes of death [17, 55-57,62]. In meta-analyses of prospective cohort studies, each daily serving of fruits or vegetables was associated with a $4 \%$ lower risk of CHD (RR $0.96,95 \%$ CI: 0.93 to 0.99 ) and a $5 \%$ lower risk of stroke (RR: $0.95,95 \%$ CI 0.92 to 0.97$)[56,57]$. Five or more daily servings of fruits and vegetables are recommended for optimal nutrition $[17,62]$. Direct observation is considered the "gold standard" for monitoring dietary intake [63-65]. However, this approach can be time consuming and impractical for use in large-scale studies. Alternatively, a food frequency questionnaire (FFQ), including the freely available National Cancer Institute Diet History Questionnaire (http://riskfactor.cancer.gov/dhq2/) [66, 67], allows for assessment of the usual patterns of food intake over an extended period of time $[68,69]$ and is considerably less burdensome in both time and cost than other measurement tools $[70,71]$.

5.1.1. Australia. In $2004 / 05,78 \%$ of the total Australian population consumed two or more servings of vegetables per day compared with just $43 \%$ of the indigenous population [13]. Similarly, 53\% of the total Australian population consumed two or more servings of fruit compared with just $26 \%$ of the indigenous population. Rates of consumption were also reportedly much lower for indigenous groups living in remote locations, wherein $20 \%$ reported no daily fruit intake and $15 \%$ no daily vegetable intake. 
5.1.2. New Zealand. In 2006/07, two out of every three adults $(64 \%)$ consumed the recommended three or more servings of vegetables each day, and $60 \%$ consumed the recommended two or more servings of fruits each day [26]. Consumption of the recommended servings of vegetables and fruits was higher for the nonindigenous (67\% and 63\%, resp.) than the indigenous population ( $62 \%$ and $56 \%$, resp.).

5.1.3. United States. Daily consumption of fruits and vegetables is poor across the general US population, with one recent study [10] estimating that only $23 \%$ of the population consume five or more servings of fruits and vegetables per day, with an even lower rate of consumption among the indigenous population (18\%). These data are consistent with other nutritional studies in indigenous communities [72-76].

5.2. Alcohol. Accumulating scientific evidence indicates that light to moderate alcohol consumption may significantly reduce the risk of CVD and all-cause mortality [77-79]. However, excessive alcohol intake is toxic to both the heart and overall health [77-79]. In particular, binge drinking, even among otherwise light drinkers, increases cardiovascular events and mortality [77-79]. Alcohol should not be universally prescribed for health enhancement owing to the lack of randomised outcome data and the potential for developing irresponsible drinking habits. The American Heart Association warns those who have never consumed alcohol against initiating such behaviours due to the inability to predict the potential for alcohol abuse [80]. Alcohol intake can be monitored using a food frequency survey (FFQ) (see above).

5.2.1. Australia. The $2004 / 05$ NATSIHS [13] reported a lower prevalence of alcohol consumption among indigenous (49\%) than nonindigenous (83\%) Australians. However, after standardizing for age, indigenous Australians are just as likely as nonindigenous Australians (15\% cf. $14 \%$, resp.) to consume higher than recommended daily intakes of alcohol $(\geq 5$ standard drinks/day for males and $\geq 4$ standard drinks/day for females). Increased alcohol consumption was reported to be greatest among remote indigenous Australians (19\%). For both groups, the prevalence of high alcohol consumption had risen by $3 \%$ since the previous (2001) NATSIHS.

5.2.2. New Zealand. In $2007 / 08$, $85 \%$ of the New Zealand population reported that they had consumed alcohol in the past year, with a slightly higher rate among the nonindigenous $(90 \%)$ than indigenous (85\%) population [81]. However, the indigenous population were twice as likely (24\% cf. $12 \%$, resp.) to exhibit excessive alcohol consumption behaviours (males: $\geq 6$ standard drinks on one occasion; females: $\geq 4$ standard drinks on one occasion).

5.2.3. United States. In $2006 / 07$, a greater portion of the nonHispanic white population had consumed alcohol in the past month compared to the indigenous population (55\% cf. $60 \%$, resp.) [82]. However, a greater proportion of the indigenous population consumed higher than the recommended levels of alcohol consumption ( $\geq 5$ standard drinks/day for $\geq 5$ days in the past 30 days) than the nonindigenous population $(12 \% \mathrm{cf}$. $8 \%$, resp.). It is important to note, however, that tribal diversity has been reported for alcohol drinking tendency $[83,84]$. Beals et al. [84] compared two culturally and geographically distinct tribes and found that current drinking rates were higher for a Northern Plains tribe than for a Southwest tribe. Gender differences have also been demonstrated, with May and Gossage [85] reporting higher levels of binge drinking among Northern tribe males than females ( 3 days cf. 1.3 days of drinking $\geq 5$ standard drinks in the past 30 days, resp.).

5.3. Physical Activity. It has been estimated that physical inactivity is responsible for $12 \%$ of the global burden of myocardial infarction [86]. Regular physical activity reduces CVD risk in its own right and also improves CVD risk factors such as obesity, hypertension, dyslipidemia, and type 2 diabetes [87-92]. The American College of Sports Medicine (ACSM) recommends at least 30 minutes of moderate-intensity physical activity (e.g., walking briskly, dancing, swimming, and bicycling) at least 5 days a week [93]. A number of tools have been developed to measure physical activity, ranging from objective measures, such as accelerometry, to subjective questionnaires [94]. While questionnaires are prone to technical error, they are inexpensive and practical for use in population studies and can provide information about physical activity type and context [94]. The International Physical Activity Questionnaire (IPAQ) (http://www.ipaq.ki.se/ipaq.htm) is a freely available, cross-national monitoring tool which has been validated for use in adults [95-99] and children [100103].

5.3.1. Australia. In 2004-05 an estimated one in three people (33\%) in Australia were sedentary, with an even higher rate (51\%) among the indigenous population [13]. Physical inactivity contributes an estimated 7\% of Australia's disease burden and $10 \%$ of all deaths [104] and accounts for $12 \%$ of the health gap between indigenous and nonindigenous Australians [105]. Despite the publicized importance of physical activity levels have remained stagnant in recent National Health Surveys $[5,13]$.

5.3.2. New Zealand. In 2006/07, half of all adults reported that they met physical activity guidelines ( $\geq 30$ mins/day on most days), with $15 \%$ of all adults identified as sedentary [26]. No significant differences were reported between indigenous and nonindigenous populations. For both ethnic groups, men were more likely to be physically active than women (55\% cf. $48 \%$, resp.), and for both groups physical activity levels remained constant between 2002/03 and 2006/07 national surveys. However, while similar physical activity levels have been reported for indigenous and nonindigenous groups, large-scale studies using validated instruments are limited. The national surveys collect physical activity data using a New Zealand version of the IPAQ. Only one study has tested the validity of the NZPAQ and reported poorer accuracy when used on Māori and Pasifika compared to European/other [106]. 
5.3.3. United States. The 2007 US National Health Interview Survey [107] estimated that $39 \%$ of all adults were sedentary, with a higher prevalence among women (41\%) versus men (37\%). Compared to the nonindigenous population, the indigenous population had a higher rate of sedentary behaviour (40\% cf. 37\%, resp.) and a lower rate of meeting prescribed physical activity (30 min/day on most days) $(10 \%$ cf. $12 \%$, resp.). These data agree with other studies showing lower rates of physical activity among indigenous Americans compared to the general population [10, 108-113].

5.4. Tobacco Use. Cigarette smoking, which is estimated to kill five million people worldwide each year [117], has been established as a risk factor for CVD since the 1940s [118]. The relationship between smoking and CVD is resultant upon the interaction of multiple mechanisms which contribute to atherosclerosis, vascular injury, vascular dysfunction, and thrombosis, although these precise mechanisms are largely unknown [119]. Cigarette smoking increases the incidence of CVD in a dose-dependent manner [120-122], with even occasional smoking increasing the risk of CVD [123]. Conversely, long-term prospective studies have demonstrated considerable mortality risk reduction with smoking cessation [124-126].

5.4.1. Australia. In 2004/05, an estimated one in five people (21\%) in Australia were smoking cigarettes daily [13]. Among the indigenous population, smoking rates are higher for those living in remote (52\%) versus nonremote (49\%) areas and particularly for males living in remote areas (58\% for males cf. $47 \%$ for females). For both ethnic groups, daily smoking prevalence declined between 2001 and 2004/05, decreasing from $49 \%$ to $46 \%$ and from $22 \%$ to $21 \%$ among indigenous and nonindigenous populations, respectively.

5.4.2. New Zealand. In 2006/07, 20\% of the New Zealand population were current cigarette smokers, with a prevalence rate that is twice as high among the indigenous (38\%, age adjusted) compared to the nonindigenous population [26]. After adjusting for age, indigenous women were more than twice as likely to be smokers than women in the total population, while indigenous men were 1.5 times more likely to smoke than men in the total population. The prevalence of smoking decreased from $23 \%$ in $2002 / 03$ to $19 \%$ in $2006 / 07$ among the total population and from $47 \%$ to $38 \%$ among the indigenous population.

5.4.3. United States. Between 2000 and 2004, cigarette smoking resulted in an estimated 443,000 premature deaths in the US each year [127]. In adults aged 35 years or over, $33 \%$ of these deaths were related to CVD. From 1965 to 2007 , smoking in the US declined by $50 \%$ among people aged 18 years or over [128]. However, despite this progress, in 2008 an estimated $21 \%$ of the total US population were current cigarette smokers [107]. The prevalence of cigarette smoking was higher among indigenous Americans at 23\%, increasing to $31 \%$ when mixed race indigenous Americans were included. There also appear to be notable differences between tribes $[10,129,130]$.

\section{Discussion}

There are more than 370 million indigenous people in 70 countries worldwide. Indigenous peoples are not monolithic; there is significant variation between and within peoples in terms of worldview, political forces, education, socioeconomic status, living conditions, and familial factors. However, many indigenous groups do share a striking commonality, a discrepancy in life expectancy when compared to their nonindigenous counterparts. Three such examples can be seen in the life expectancy of indigenous groups in Australia, New Zealand, and America. A higher prevalence of CVD may be considered the driving force behind this discrepancy [1], which is being fuelled by lifestyle and subsequent cardiometabolic risk factors.

The indigenous populations from each of these nations exhibit a cluster of cardiometabolic conditions. Compared to their respective nonindigenous counterparts, all three indigenous groups have higher rates of obesity and diabetes, hypertension is greater for the indigenous populations of New Zealand and Australia, and high cholesterol is greater among indigenous groups in the United States. While each of these conditions has independently been shown to accelerate CVD [131-134], the effects are also thought to be additive [34]. Poor lifestyle choices may precede and contribute to these cardiometabolic outcomes. Compared to their nonindigenous counterparts, all three indigenous groups exhibit higher rates of smoking and dangerous alcohol behaviour, as well as lower consumption of fruits and vegetables. The indigenous groups of Australia and the United States also exhibit greater rates of sedentary behaviour, while there remains a need to collect valid physical activity data in New Zealand [106].

Holistic strategies, which recognize the complex interactions between lifestyle factors, may assist in promoting positive changes. For example, a recent systematic review and meta-analysis [135] reported that physical activity interventions have had only a small effect on children's overall activity levels. This implies that lifestyle strategies to promote physical activity should be sensitive to total daily physical activity as well as other lifestyle factors, including nutrition and sleep behaviour, each of which may be influenced by increased physical activity levels and may affect cardiometabolic outcomes $[136,137]$.

In order to maximize potential positive outcomes, strategies which aim to promote positive changes in lifestyle should not only be physiologically appropriate; they should also be sensitive to sociocultural norms. For example, within Australia an indigenous person's connections to family, ancestors, the wider community, and the land are very important to the choices they make about all aspects of their lives [138]. Exercising alone for personal benefit may prevent a person from spending time with family and loved ones, and this may be seen as superficial. Similarly, the Māori people of New Zealand show a decided preference for physical activities which involve whanaungatanga/kotahitanga (a team 
environment), a forum to experience feelings of whanau (extended family) [139]. In this regard an argument can be made that appropriate physical activity prescription can be used as a vehicle to experience, discover, and reconnect to indigenous cultural heritage [140]. However, it must also be recognized that sociocultural norms may substantially differ by group, including within a given nation. For example, in the United States there are 566 federally recognized tribes [9], with different histories, unique languages, varied cultural traditions, and various degrees of societal assimilation [10].

Even within a given nation, strategies to promote lifestyle changes must be specific to a group, not to the population as a whole, especially when a geographical area includes different language and culturally distinct groups [141]. Diversity competence involves knowledge, skills, and abilities that enable a researcher to deal with a specific population. The National Standards for Culturally and Linguistically Appropriate Services in Health and Health Care (the National CLAS Standards) [142] in the United States intend to advance health equity, improve quality, and help eliminate health care disparities by providing a blueprint for individuals and health and health care organizations to implement culturally and linguistically appropriate services. Adoption of these standards is highly recommended for health care providers interested in respecting such diversity competences.

\section{Limitations}

To ensure reliable comparisons between ethnic groups, the largest data sources available were utilized for a given cohort (nation), where available. Wherever large data sets were not available, reliable sets of relevant data were used to consolidate thought and formulate a comprehensive picture. All data used in the current publication spanned from 2002 to 2012. This would have introduced selection and methodological and historical bias, limiting our ability to make accurate comparisons across nations. Furthermore, the preponderance of the literature on the health of indigenous populations is focused on describing or understanding problems [143], rather than on testing the effectiveness of potential solutions. Further studies are required to determine causality between lifestyle and cardiometabolic risk factors and to determine whether causality is moderated by ethnicity.

\section{Implications}

This review has described the relationship between common lifestyle choices, cardiometabolic conditions (i.e., lifestylerelated disease), and CVD. It is evident that disparities in CVD prevalence, mortality, and associated risk factors exist between indigenous and nonindigenous populations. Causality, however, has yet to be conclusively determined and is essential if we are to develop effective solutions for decreasing disease burden in a number of groups. While the described model will assist future research focusing on indigenous health outcomes, it must also be recognised that such research must be sensitive to differences in culture between indigenous groups within a country, in addition to being sensitive to national cultural norms.

\section{Conflict of Interests}

The authors declare that there is no conflict of interests regarding the publication of this paper.

\section{References}

[1] M. D. Huffman and J. M. Galloway, "Cardiovascular health in indigenous communities: successful programs," Heart Lung and Circulation, vol. 19, no. 5-6, pp. 351-360, 2010.

[2] G. Danaei, E. L. Ding, D. Mozaffarian et al., "The preventable causes of death in the United States: comparative risk assessment of dietary, lifestyle and metabolic risk factors," PLoS Medicine, vol. 6, no. 4, Article ID e1000058, 2009.

[3] A. H. Mokdad, J. S. Marks, D. F. Stroup, and J. L. Gerberding, "Actual causes of death in the United States, 2000," Journal of the American Medical Association, vol. 291, no. 10, pp. 1238-1245, 2004.

[4] L. Stoner, S. P. Shultz, D. M. Lambrick, J. Krebs, M. Weatherall, and B. R. Palmer, "The combating obesity in Māori and Pasifika adolescent school-children study: COMPASS methodology and study protocol," International Journal of Preventive Medicine, vol. 4, no. 5, pp. 67-81, 2013.

[5] AIHW, "Australia’s health 2006," Australian Institute of Health and Welfare, Canberra, Australia, 2006.

[6] SNZ, “Census 2006," 2007, http://www.stats.govt.nz/Census/ 2006CensusHomePage.aspx.

[7] USCB, “Census data 2010," 2011, http://2010.census.gov/2010census/data/index.php.

[8] USCB, "U.S. Hispanic Population Surpasses 45 Million Now 15 Percent of Total," 2008, http://www.census.gov/newsroom/ releases/archives/population/cb08-67.html.

[9] Affairs UDoII, “Tribal directory," 2013.

[10] J. E. Holm, N. Vogeltanz-Holm, D. Poltavski, and L. McDonald, "Assessing health status, behavioral risks, and health disparities in American Indians living on the northern plains of the U.S," Public Health Reports, vol. 125, no. 1, pp. 68-78, 2010.

[11] T. Norris, P. L. Vines, and E. M. Hoeffel, The American Indian and Alaska Native Population: 2010, US Census Bureau, Washington, DC, USA, 2010.

[12] T. A. Gaziano, "Cardiovascular disease in the developing world and its cost-effective management," Circulation, vol. 112, no. 23, pp. 3547-3553, 2005.

[13] ABS, National Aboriginal and Torres Strait Islander Health Survey, 2004-05, Australian Bureau of Statistics, Canberra, Australia, 2006.

[14] MOH, Mortality and Demographic Data 2004, Ministry of Health, Wellington, New Zealand, 2007.

[15] M. Tobias, K. Sexton, S. Mann, and N. Sharpe, "How low can it go? projecting ischaemic heart disease mortality in New Zealand to 2015," New Zealand Medical Journal, vol. 119, no. 1232, 2006.

[16] W. C. Chan, C. Wright, T. Riddell et al., "Ethnic and socioeconomic disparities in the prevalence of cardiovascular disease in New Zealand," New Zealand Medical Journal, vol. 121, no. 1285, pp. 11-20, 2008. 
[17] D. Lloyd-Jones, R. J. Adams, T. M. Brown, M. Carnethon, S. Dai, and G. De Simone, "Heart disease and stroke statistics2010 update: a report from the American heart association," Circulation, vol. 121, no. 7, pp. e46-e215, 2010.

[18] R. N. Anderson, "U.S. decennial life tables for 1989-91," in United States Life Tables Eliminating Certain Causes of Death, vol. 1, Hyattsville, Md, USA, National Center for Health Statistics, 1999.

[19] IHS, Facts on Indian Health Disparities, Indian Health Service, Rockville, Md, USA, 2006.

[20] P. W. Wilson, R. B. D’Agostino, L. Sullivan, H. Parise, and W. B. Kannel, "Overweight and obesity as determinants of cardiovascular risk: the framingham experience," Archives of Internal Medicine, vol. 162, no. 16, pp. 1867-1872, 2002.

[21] M. Chrostowska, A. Szyndler, P. Paczwa, and K. Narkiewicz, "Impact of abdominal obesity on the frequency of hypertension and cardiovascular disease in Poland-results from the IDEA study (international day for the evaluation of abdominal obesity)," Blood Pressure, vol. 20, no. 3, pp. 145-152, 2011.

[22] B. Balkau, J. E. Deanfield, J. P. Despres et al., "International day for the evaluation of abdominal obesity (IDEA): a study of waist circumference, cardiovascular disease, and diabetes mellitus in 168,000 primary care patients in 63 countries," Circulation, vol. 116, no. 17, pp. 1942-1951, 2007.

[23] B. Cepeda-Valery, G. S. Pressman, V. M. Figueredo, and A. Romero-Corral, "Impact of obesity on total and cardiovascular mortality-fat or fiction?" Nature Reviews Cardiology, vol. 8, no. 4, pp. 233-237, 2011.

[24] M. Li and R. A. McDermott, "Using anthropometric indices to predict cardio-metabolic risk factors in Australian indigenous populations," Diabetes Research and Clinical Practice, vol. 87, no. 3, pp. 401-406, 2010.

[25] S. A. Lear, P. T. James, G. T. Ko, and S. Kumanyika, "Appropriateness of waist circumference and waist-to-hip ratio cutoffs for different ethnic groups," European Journal of Clinical Nutrition, vol. 64, no. 1, pp. 42-61, 2010.

[26] MOH, A Potrait of Health: Key Results of the 2006-07 New Zealand Health Survey, Ministry of Health, Wellington, New Zealand, 2008.

[27] WHO, Definition, Diagnosis and Classification of Diabetes Mellitus and Its Complications. Part 1: Diagnosis and Classification of Diabetes Mellitus, World Health Organization, Geneva, Switzerland, 1999.

[28] ADA, "Diagnosis and classification of diabetes mellitus," Diabetes Care, vol. 34, Supplement 1, pp. S62-S69, 2011.

[29] S. Wild, G. Roglic, A. Green, R. Sicree, and H. King, "Global prevalence of diabetes: estimates for the year 2000 and projections for 2030," Diabetes Care, vol. 27, no. 5, pp. 1047-1053, 2004.

[30] E. S. Ford, G. Zhao, and C. Li, "Pre-diabetes and the risk for cardiovascular disease: a systematic review of the evidence," Journal of the American College of Cardiology, vol. 55, no. 13, pp. 1310-1317, 2010.

[31] L. G. Mellbin, M. Anselmino, and L. Ryden, "Diabetes, prediabetes and cardiovascular risk," European Journal of Cardiovascular Prevention and Rehabilitation, vol. 17, Supplement 1, pp. S9-S14, 2010.

[32] C. S. Fox, "Cardiovascular disease risk factors, type 2 diabetes mellitus and the framingham heart study," Trends in Cardiovascular Medicine, vol. 20, no. 3, pp. 90-95, 2010.

[33] S. R. Preis, M. J. Pencina, S. J. Hwang et al., "Trends in cardiovascular disease risk factors in individuals with and without diabetes mellitus in the framingham heart study," Circulation, vol. 120, no. 3, pp. 212-220, 2009.

[34] T. Nakagami, Q. Qiao, J. Tuomilehto et al., "Screen-detected diabetes, hypertension and hypercholesterolemia as predictors of cardiovascular mortality in five populations of Asian origin: the DECODA study," European Journal of Cardiovascular Prevention and Rehabilitation, vol. 13, no. 4, pp. 555-561, 2006.

[35] S. N. Rajpathak, V. Aggarwal, and F. B. Hu, "Multifactorial intervention to reduce cardiovascular events in type 2 diabetes," Current Diabetes Reports, vol. 10, no. 1, pp. 16-23, 2010.

[36] A. Chudyk and R. J. Petrella, "Effects of exercise on cardiovascular risk factors in type 2 diabetes: a meta-analysis," Diabetes Care, vol. 34, no. 5, pp. 1228-1237, 2011.

[37] M. R. Salazar, H. A. Carbajal, W. G. Espeche et al., "Relationships among insulin resistance, obesity, diagnosis of the metabolic syndrome and cardio-metabolic risk," Diabetes and Vascular Disease Research, vol. 8, no. 2, pp. 109-116, 2011.

[38] G. M. Reaven, "Relationships among insulin resistance, type 2 diabetes, essential hypertension, and cardiovascular disease: similarities and differences," Journal of Clinical Hypertension, vol. 13, no. 4, pp. 238-243, 2011.

[39] D. W. Bowden, A. J. Cox, B. I. Freedman et al., "Review of the diabetes heart study (DHS) family of studies: a comprehensively examined sample for genetic and epidemiological studies of type 2 diabetes and its complications," The Review of Diabetic Studies, vol. 7, no. 3, pp. 188-201, 2010.

[40] A. V. Chobanian, G. L. Bakris, H. R. Black et al., "The seventh report of the joint national committee on prevention, detection, evaluation, and treatment of high blood pressure: the JNC 7 report," Journal of the American Medical Association, vol. 289, no. 19, pp. 2560-2572, 2003.

[41] ABS, National Health Survey: Summary of Results, 2007-2008, Australian Bureau of Statistics, Canberra, Australia, 2009.

[42] J. Jeppesen, T. W. Hansen, S. Rasmussen, H. Ibsen, and C. Torp-Pedersen, "Metabolic syndrome, low-density lipoprotein cholesterol, and risk of cardiovascular disease: a populationbased study," Atherosclerosis, vol. 189, no. 2, pp. 369-374, 2006.

[43] D. G. Karalis, "Intensive lowering of low-density lipoprotein cholesterol levels for primary prevention of coronary artery disease," Mayo Clinic Proceedings, vol. 84, no. 4, pp. 345-352, 2009.

[44] T. Teramoto, N. Nakaya, S. Yokoyama, Y. Ohashi, K. Mizuno, and H. Nakamura, "Association between lowering low-density lipoprotein cholesterol with pravastatin and primary prevention of cardiovascular disease in mild to moderate hypercholesterolemic Japanese," Journal of Atherosclerosis and Thrombosis, vol. 17, no. 8, pp. 879-887, 2010.

[45] E. V. De Freitas, A. A. Brandao, R. Pozzan et al., "Importance of high-density lipoprotein-cholesterol (HDL-C) levels to the incidence of cardiovascular disease (CVD) in the elderly," Archives of Gerontology and Geriatrics, vol. 52, no. 2, pp. 217222, 2011.

[46] E. Windler, M. Schoffauer, and B. C. Zyriax, "The significance of low HDL-cholesterol levels in an ageing society at increased risk for cardiovascular disease," Diabetes and Vascular Disease Research, vol. 4, no. 2, pp. 136-142, 2007.

[47] M. Briel, I. Ferreira-Gonzalez, J. J. You et al., "Association between change in high density lipoprotein cholesterol and cardiovascular disease morbidity and mortality: systematic review and meta-regression analysis," The British Medical Journal, vol. 338, no. 7693, 2009. 
[48] M. H. Davidson, "Targeting high-density lipoprotein cholesterol in the management of cardiovascular disease," The American Heart Hospital Journal, vol. 5, no. 4, pp. 210-216, 2007.

[49] N. J. Stone, S. Bilek, and S. Rosenbaum, "Recent national cholesterol education program adult treatment panel III update: adjustments and options," The American Journal of Cardiology, vol. 96, no. 4, Supplement, pp. 53-59, 2005.

[50] A. V. Chobanian, G. L. Bakris, H. R. Black et al., "Seventh report of the joint national committee on prevention, detection, evaluation and treatment of high blood pressure," Hypertension, vol. 42, no. 6, pp. 1206-1252, 2003.

[51] O. H. Franco, A. Peeters, L. Bonneux, and C. De Laet, "Blood pressure in adulthood and life expectancy with cardiovascular disease in men and women: life course analysis," Hypertension, vol. 46 , no. 2 , pp. 280-286, 2005.

[52] WHO, "The world health report 2002," World Health Organization, Geneva, Switzerland, 2002.

[53] C. M. Lawes, S. Vander Hoorn, M. R. Law, P. Elliott, S. MacMahon, and A. Rodgers, "Blood pressure and the global burden of disease 2000. part 1: estimates of blood pressure levels," Journal of Hypertension, vol. 24, no. 3, pp. 413-422, 2006.

[54] V. L. Roger, A. S. Go, D. M. Lloyd-Jones et al., "Heart disease and stroke statistics-2012 update: a report from the American heart association," Circulation, vol. 125, no. 1, pp. e2-e220, 2012.

[55] F. J. He, C. A. Nowson, M. Lucas, and G. A. MacGregor, "Increased consumption of fruit and vegetables is related to a reduced risk of coronary heart disease: meta-analysis of cohort studies," Journal of Human Hypertension, vol. 21, no. 9, pp. 717728, 2007.

[56] L. Dauchet, P. Amouyel, S. Hercberg, and J. Dallongeville, "Fruit and vegetable consumption and risk of coronary heart disease: a meta-analysis of cohort studies," Journal of Nutrition, vol. 136, no. 10, pp. 2588-2593, 2006.

[57] L. Dauchet, P. Amouyel, and J. Dallongeville, "Fruit and vegetable consumption and risk of stroke: a meta-analysis of cohort studies," Neurology, vol. 65, no. 8, pp. 1193-1197, 2005.

[58] C. Nishida and R. Uauy, "WHO scientific update on health consequences of trans fatty acids: introduction," European Journal of Clinical Nutrition, vol. 63, no. 2, pp. S1-S4, 2009.

[59] P. N. Mitrou, V. Kipnis, A. C. Thiebaut et al., "Mediterranean dietary pattern and prediction of all-cause mortality in a US population: results from the NIH-AARP diet and health study," Archives of Internal Medicine, vol. 167, no. 22, pp. 2461-2468, 2007.

[60] D. R. Keast, C. E. O’Neil, and J. M. Jones, "Dried fruit consumption is associated with improved diet quality and reduced obesity in US adults: national health and nutrition examination survey, 1999-2004," Nutrition Research, vol. 31, no. 6, pp. 460467, 2011.

[61] C. Agostoni, C. Braegger, T. Decsi et al., "Role of dietary factors and food habits in the development of childhood obesity: a commentary by the ESPGHAN committee on nutrition," Journal of Pediatric Gastroenterology and Nutrition, vol. 52, no. 6, pp. 662-669, 2011.

[62] CDC, "State-specific trends in fruit and vegetable consumption among adults-United States, 2000-2009," Morbidity and Mortality Weekly Report, vol. 59, no. 35, pp. 1125-11130, 2010.

[63] G. C. Frank, "Taking a bite out of eating behavior: food records and food recalls of children," The Journal of School Health, vol. 61, no. 5, pp. 198-200, 1991.
[64] W. Mertz, "Food intake measurements: is there a "gold standard"?" Journal of the American Dietetic Association, vol. 92, no. 12, pp. 1463-1465, 1992.

[65] G. Block, "A review of validations of dietary assessment methods," The American Journal of Epidemiology, vol. 115, no. 4, pp. 492-505, 1982.

[66] A. Flood, A. F. Subar, S. G. Hull, T. P. Zimmerman, D. J. Jenkins, and A. Schatzkin, "Methodology for adding glycemic load values to the national cancer institute diet history questionnaire database," Journal of the American Dietetic Association, vol. 106, no. 3, pp. 393-402, 2006.

[67] A. E. Millen, D. Midthune, F. E. Thompson, V. Kipnis, and A. F. Subar, "The national cancer institute diet history questionnaire: validation of pyramid food servings," American Journal of Epidemiology, vol. 163, no. 3, pp. 279-288, 2006.

[68] A. F. Subar, “Developing dietary assessment tools," Journal of the American Dietetic Association, vol. 104, no. 5, pp. 769-770, 2004.

[69] T. C. Carithers, S. A. Talegawkar, M. L. Rowser et al., "Validity and calibration of food frequency questionnaires used with African-American adults in the Jackson heart study," Journal of the American Dietetic Association, vol. 109, no. 7, pp. 1184-1193, 2009.

[70] L. H. Kushi, "Gaps in epidemiologic research methods: design considerations for studies that use food-frequency questionnaires," The American Journal of Clinical Nutrition, vol. 59, Supplement 1, pp. 180S-184S, 1994.

[71] W. Willett, Nutritional Epidemiology, Oxford University Press, New York, NY, USA, 2nd edition, 1998.

[72] L. Harnack, N. Sherwood, and M. Story, "Diet and physical activity patterns of urban American Indian women," American Journal of Health Promotion, vol. 13, no. 4, pp. 233-236, 1999.

[73] L. Harnack, M. Story, and B. H. Rock, "Diet and physical activity patterns of Lakota Indian adults," Journal of the American Dietetic Association, vol. 99, no. 7, pp. 829-835, 1999.

[74] B. DeGonzague, O. Receveur, D. Wedll, and H. V. Kuhnlein, "Dietary intake and body mass index of adults in 2 Ojibwe communities," Journal of the American Dietetic Association, vol. 99, no. 6, pp. 710-716, 1999.

[75] S. E. Jones, K. Anderson, R. Lowry, and H. Conner, "Risks to health among American Indian/Alaska native high school students in the United States," Preventing Chronic Disease, vol. 8, no. 4, article A76, 2011.

[76] T. L. LaRowe, A. K. Adams, J. B. Jobe, K. A. Cronin, S. M. Vannatter, and R. J. Prince, "Dietary intakes and physical activity among preschool-aged children living in rural American Indian communities before a family-based healthy lifestyle intervention," Journal of the American Dietetic Association, vol. 110, no. 7, pp. 1049-1057, 2010.

[77] P. E. Ronksley, S. E. Brien, B. J. Turner, K. J. Mukamal, and W. A. Ghali, "Association of alcohol consumption with selected cardiovascular disease outcomes: a systematic review and metaanalysis," The British Medical Journal, vol. 342, article d671, 2011.

[78] G. Corrao, L. Rubbiati, V. Bagnardi, A. Zambon, and K. Poikolainen, "Alcohol and coronary heart disease: a metaanalysis," Addiction, vol. 95, no. 10, pp. 1505-1523, 2000.

[79] J. H. O'Keefe, K. A. Bybee, and C. J. Lavie, "Alcohol and cardiovascular health. the razor-sharp double-edged sword," Journal of the American College of Cardiology, vol. 50, no. 11, pp. 1009-1014, 2007. 
[80] D. L. Lucas, R. A. Brown, M. Wassef, and T. D. Giles, "Alcohol and the cardiovascular system: research challenges and opportunities," Journal of the American College of Cardiology, vol. 45, no. 12, pp. 1916-1924, 2005.

[81] MOH, Alcohol Use in New Zealand: Key Results of the 2007/08 New Zealand Alcohol and Drug Use Survey, Ministry of Health, Wellington, New Zealand, 2009.

[82] SAMHSA, "2007 National survey on drug use and health, detailed tables, dependence, abuse and treatment, table 2.46B," 2008, http://oas.samhsa.gov/NSDUH/2k7NSDUH/tabs/Sect2peTabs43to84.htm\#Tab2.

[83] W. J. Szlemko, J. W. Wood, and P. J. Thurman, "Native Americans and alcohol: past, present, and future," Journal of General Psychology, vol. 133, no. 4, pp. 435-451, 2006.

[84] J. Beals, P. Spicer, C. M. Mitchell et al., "Racial disparities in alcohol use: comparison of 2 American Indian reservation populations with national data," American Journal of Public Health, vol. 93, no. 10, pp. 1683-1685, 2003.

[85] P. A. May and P. Gossage, "New data on the epidemiology of adult drinking and substance use among American Indians of the northern states: male and female data on prevalence, patterns and consequences," American Indian and Alaska Native Mental Health Research, vol. 10, no. 2, pp. 1-26, 2001.

[86] S. Yusuf, S. Hawken, S. Ounpuu et al., "Effect of potentially modifiable risk factors associated with myocardial infarction in 52 countries (the INTERHEART study): case-control study," Lancet, vol. 364, no. 9438, pp. 937-952, 2004.

[87] J. Sattelmair, J. Pertman, E. L. Ding, H. W. Kohl III, W. Haskell, and I. M. Lee, "Dose response between physical activity and risk of coronary heart disease: a meta-analysis," Circulation, vol. 124, no. 7, pp. 789-795, 2011.

[88] K. Mansikkaniemi, M. Juonala, S. Taimela, M. Hirvensalo, R. Telama, and R. Huupponen, "Cross-sectional associations between physical activity and selected coronary heart disease risk factors in young adults. the cardiovascular risk in young finns study," Annals of Medicine, vol. 44, no. 7, pp. 733-744, 2011.

[89] T. Moholdt, U. Wisloff, T. I. Nilsen, and S. A. Slordahl, "Physical activity and mortality in men and women with coronary heart disease: a prospective population-based cohort study in Norway (the HUNT study)," The European Journal of Cardiovascular Prevention and Rehabilitation, vol. 15, no. 6, pp. 639-645, 2008.

[90] T. Church, "Exercise in obesity, metabolic syndrome, and diabetes," Progress in Cardiovascular Diseases, vol. 53, no. 6, pp. 412-418, 2011.

[91] S. Carroll and M. Dudfield, "What is the relationship between exercise and metabolic abnormalities? A review of the metabolic syndrome," Sports Medicine, vol. 34, no. 6, pp. 371-418, 2004.

[92] A. N. Long and S. Dagogo-Jack, "Comorbidities of diabetes and hypertension: mechanisms and approach to target organ protection," Journal of Clinical Hypertension, vol. 13, no. 4, pp. 244-251, 2011.

[93] C. E. Garber, B. Blissmer, M. R. Deschenes et al., "American college of sports medicine position stand. quantity and quality of exercise for developing and maintaining cardiorespiratory, musculoskeletal and neuromotor fitness in apparently healthy adults: guidance for prescribing exercise," Medicine and Science in Sports and Exercise, vol. 43, no. 7, pp. 1334-1359, 2011.

[94] J. Dollman, A. D. Okely, L. Hardy, A. Timperio, J. Salmon, and A. P. Hills, "A hitchhiker's guide to assessing young people's physical activity: deciding what method to use," Journal of Science and Medicine in Sport, vol. 12, no. 5, pp. 518-525, 2009.
[95] M. A. Alomari, E. F. Keewan, R. Qhatan et al., "Blood pressure and circulatory relationships with physical activity level in young normotensive individuals: IPAQ validity and reliability considerations," Clinical and Experimental Hypertension, vol. 33, no. 5, pp. 345-353, 2011.

[96] A. Bauman, B. E. Ainsworth, J. F. Sallis et al., "The descriptive epidemiology of sitting a 20-country comparison using the international physical activity questionnaire (IPAQ)," The American Journal of Preventive Medicine, vol. 41, no. 2, pp. 228235, 2011.

[97] S. M. Schembre and D. A. Riebe, "Non-exercise estimation of $\mathrm{VO}(2)$ max using the international physical activity questionnaire," Measurement in Physical Education and Exercise Science, vol. 15, no. 3, pp. 168-181, 2011.

[98] K. Tomioka, J. Iwamoto, K. Saeki, and N. Okamoto, "Reliability and validity of the international physical activity questionnaire (IPAQ) in elderly adults: the Fujiwara-kyo study," Journal of Epidemiology, vol. 21, no. 6, pp. 459-465, 2011.

[99] C. L. Craig, A. L. Marshall, M. Sjostrom et al., "International physical activity questionnaire: 12 -country reliability and validity," Medicine and Science in Sports and Exercise, vol. 35, no. 8, pp. 1381-1395, 2003.

[100] C. Ottevaere, I. Huybrechts, I. De Bourdeaudhuij et al., "Comparison of the IPAQ-A and actigraph in relation to $\mathrm{VO}_{2} \mathrm{max}$ among European adolescents: the HELENA study," Journal of Science and Medicine in Sport, vol. 14, no. 4, pp. 317-324, 2011.

[101] V. Rangul, T. L. Holmen, N. Kurtze, K. Cuypers, and K. Midthjell, "Reliability and validity of two frequently used selfadministered physical activity questionnaires in adolescents," BMC Medical Research Methodology, vol. 8, article 47, 2008.

[102] M. Hagstromer, P. Bergman, I. De Bourdeaudhuij et al., "Concurrent validity of a modified version of the international physical activity questionnaire (IPAQ-A) in European adolescents: the HELENA Study," International Journal of Obesity, vol. 32, no. 5, pp. S42-S48, 2008.

[103] C. Ottevaere, I. Huybrechts, F. De Meester, I. De Bourdeaudhuij, M. Cuenca-Garcia, and S. De Henauw, "The use of accelerometry in adolescents and its implementation with non-wear time activity diaries in free-living conditions," Journal of Sports Sciences, vol. 29, no. 1, pp. 103-113, 2011.

[104] AIHW, The Burden of Disease and Injury in Australia 2003, Australian Institute of Health and Welfare (AIHW), Canberra, New Zealand, 2007.

[105] T. Vos, B. Barker, S. Begg, L. Stanley, and A. D. Lopez, "Burden of disease and injury in Aboriginal and Torres Strait Islander peoples: the indigenous health gap," International Journal of Epidemiology, vol. 38, no. 2, pp. 470-477, 2009.

[106] K. L. Moy, R. K. Scragg, G. McLean, and H. Carr, "The New Zealand physical activity questionnaires: validation by heartrate monitoring in a multiethnic population," Journal of Physical Activity and Health, vol. 5, no. 1, pp. S45-S61, 2008.

[107] J. R. Pleis, J. W. Lucas, and B. W. Ward, "Summary health statistics for U.S. adults: national health interview survey, 2008," Vital and Health Statistics, vol. 10, no. 242, pp. 1-157, 2009.

[108] A. K. Kurian and K. M. Cardarelli, "Racial and ethnic differences in cardiovascular disease risk factors: a systematic review," Ethnicity and Disease, vol. 17, no. 1, pp. 143-152, 2007.

[109] C. B. Steele, C. J. Cardinez, L. C. Richardson, L. Tom-Orme, and K. M. Shaw, "Surveillance for health behaviors of American Indians and Alaska natives-findings from the behavioral risk factor surveillance system, 2000-2006," Cancer, vol. 113, Supplement 5, pp. 1131-1141, 2008. 
[110] C. H. Denny, D. Holtzman, and N. Cobb, "Surveillance for health behaviors of American Indians and Alaska natives. findings from the behavioral risk factor surveillance system, 1997-2000," Morbidity and Mortality Weekly Report, vol. 52, no. 7, pp. 1-13, 2003.

[111] F. S. Hodge, B. G. Cantrell, and S. Kim, "Health status and sociodemographic characteristics of the morbidly obese American Indians," Ethnicity and Disease, vol. 21, no. 1, pp. 52-57, 2011.

[112] G. E. Duncan, J. Goldberg, D. Buchwald, Y. Wen, and J. A. Henderson, "Epidemiology of physical activity in American Indians in the education and research towards health cohort," American Journal of Preventive Medicine, vol. 37, no. 6, pp. 488494, 2009.

[113] K. L. Storti, V. C. Arena, M. M. Barmada et al., "Physical activity levels in American-Indian adults. the strong heart family study," The American Journal of Preventive Medicine, vol. 37, no. 6, pp. 481-487, 2009.

[114] ABS, Population Distribution, Aboriginal and Torres Strait Islander Australians, 2006, Australian Bureau of Statistics, Canberra, Australia, 2007.

[115] AIHW, "Life expectancy," 2011, http://www.aihw.gov.au/lifeexpectancy/.

[116] SNZ, "New Zealand life tables: 2005-07," 2008, http://www .stats.govt.nz/browse_for_stats/health/life_expectancy/nzlifetables_hotp05-07.aspx.

[117] C. D. Mathers and D. Loncar, "Projections of global mortality and burden of disease from 2002 to 2030," PLoS Medicine, vol. 3, no. 11, article e442, 2006.

[118] M. R. Law, J. K. Morris, and N. J. Wald, "Environmental tobacco smoke exposure and ischaemic heart disease: an evaluation of the evidence," The British Medical Journal, vol. 315, no. 7114, pp. 973-980, 1997.

[119] J. A. Ambrose and R. S. Barua, "The pathophysiology of cigarette smoking and cardiovascular disease: an update," Journal of the American College of Cardiology, vol. 43, no. 10, pp. 1731-1737, 2004.

[120] D. Conen, B. M. Everett, T. Kurth et al., "Smoking, smoking status, and risk for symptomatic peripheral artery disease in women," Annals of Internal Medicine, vol. 154, no. 11, pp. 719726, 2011.

[121] Y. H. Lee, M. H. Shin, S. S. Kweon et al., "Cumulative smoking exposure, duration of smoking cessation and peripheral arterial disease in middle-aged and older Korean men," BMC Public Health, vol. 11, article 94, 2011.

[122] H. Tomiyama, H. Hashimoto, H. Tanaka et al., "Continuous smoking and progression of arterial stiffening: a prospective study," Journal of the American College of Cardiology, vol. 55, no. 18, pp. 1979-1987, 2010.

[123] L. Stoner, M. J. Sabatier, C. D. Black, and K. K. McCully, "Occasional cigarette smoking chronically affects arterial function," Ultrasound in Medicine and Biology, vol. 34, no. 12, pp. 18851892, 2008.

[124] R. Doll, R. Peto, J. Boreham, and I. Sutherland, "Mortality in relation to smoking: 50 years' observations on male British doctors," The British Medical Journal, vol. 328, no. 7455, pp. 15191528, 2004.

[125] K. Wilson, N. Gibson, A. Willan, and D. Cook, "Effect of smoking cessation on mortality after myocardial infarction: meta-analysis of cohort studies," Archives of Internal Medicine, vol. 160, no. 7, pp. 939-944, 2000.
[126] J. A. Critchley and S. Capewell, "Mortality risk reduction associated with smoking cessation in patients with coronary heart disease: a systematic review," Journal of the American Medical Association, vol. 290, no. 1, pp. 86-97, 2003.

[127] CDC, "Smoking-attributable mortality, years of potential life lost, and productivity losses: United States, 2000-2004," Morbidity and Mortality Weekly Report, vol. 57, pp. 1226-1228, 2008.

[128] NCHS, Health, United States, 2008 With Chartbook, National Center for Health Statistics, Hyattsville, Md, USA, 2009.

[129] J. E. Eichner, W. Wang, Y. Zhang, E. T. Lee, and T. K. Welty, "Tobacco use and cardiovascular disease among American Indians: the strong heart study," International Journal of Environmental Research and Public Health, vol. 7, no. 10, pp. 38163830, 2010.

[130] J. J. Smith, E. D. Ferucci, D. A. Dillard, and A. P. Lanier, "Tobacco use among Alaska native people in the EARTH study," Nicotine and Tobacco Research, vol. 12, no. 8, pp. 839-844, 2010.

[131] N. Mattsson, T. Ronnemaa, M. Juonala et al., "Arterial structure and function in young adults with the metabolic syndrome: the cardiovascular risk in young finns study," The European Heart Journal, vol. 29, no. 6, pp. 784-791, 2008.

[132] S. M. Kerr, M. B. Livingstone, T. A. McCrorie, and J. M. Wallace, "Endothelial dysfunction associated with obesity and the effect of weight loss interventions," Proceedings of the Nutrition Society, vol. 70, no. 4, pp. 418-425, 2011.

[133] V. Palmieri, C. Russo, S. Pezzullo, M. N. Di Minno, and A. Celentano, "Relation of flow-mediated dilation to global arterial load: impact of hypertension and additional cardiovascular risk factors," International Journal of Cardiology, vol. 152, no. 2, pp. 225-230, 2011.

[134] S. Bleda, J. De Haro, C. Varela, L. Esparza, J. Rodriguez, and F. Acin, "Improving total-cholesterol/HDL-cholesterol ratio results in an endothelial dysfunction recovery in peripheral artery disease patients," Cholesterol, vol. 2012, Article ID 895326, 6 pages, 2012.

[135] B. Metcalf, W. Henley, and T. Wilkin, "Effectiveness of intervention on physical activity of children: systematic review and meta-analysis of controlled trials with objectively measured outcomes (EarlyBird 54)," The British Medical Journal, vol. 345, article e5888, 2012.

[136] S. Javaheri, A. Storfer-Isser, C. L. Rosen, and S. Redline, "Sleep quality and elevated blood pressure in adolescents," Circulation, vol. 118, no. 10, pp. 1034-1040, 2008.

[137] S. Javaheri, A. Storfer-Isser, C. L. Rosen, and S. Redline, "Association of short and long sleep durations with insulin sensitivity in adolescents," Journal of Pediatrics, vol. 158, no. 4, pp. 617-623, 2011.

[138] BHC, "Aboriginal health-barriers to physical activity," 2012, http://www.betterhealth.vic.gov.au/bhcv2/bhcarticles.nsf/ pages/Aboriginal_health_physical_activity.

[139] P. Te Rito, "Leadership in Māori, European cultures and in the world of sport," MAI Review, vol. 1, no. 8, pp. 1-19, 2006.

[140] P. Bergin, "Maori sport and cultural identity in Australia," The Australian Journal of Anthropology, vol. 13, no. 3, pp. 257-269, 2002.

[141] L. M. Jamieson, Y. C. Paradies, S. Eades, A. Chong, L. MapleBrown, and P. Morris, "Ten principles relevant to health research among Indigenous Australian populations," The Medical Journal Australia, vol. 197, no. 1, pp. 16-18, 2012. 
[142] OMH, "The national CLAS standards," 2013, http://minorityhealth.hhs.gov/templates/browse.aspx?lvl=2\&lvlID $=15$.

[143] C. L. Paul, R. Sanson-Fisher, J. Stewart, and A. E. Anderson, "Being sorry is not enough. the sorry state of the evidence base for improving the health of indigenous populations," The American Journal of Preventive Medicine, vol. 38, no. 5, pp. 566568, 2010. 


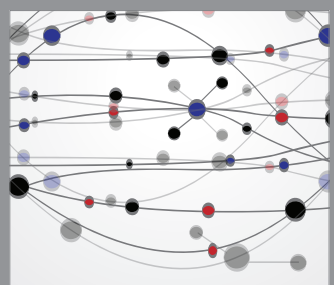

The Scientific World Journal
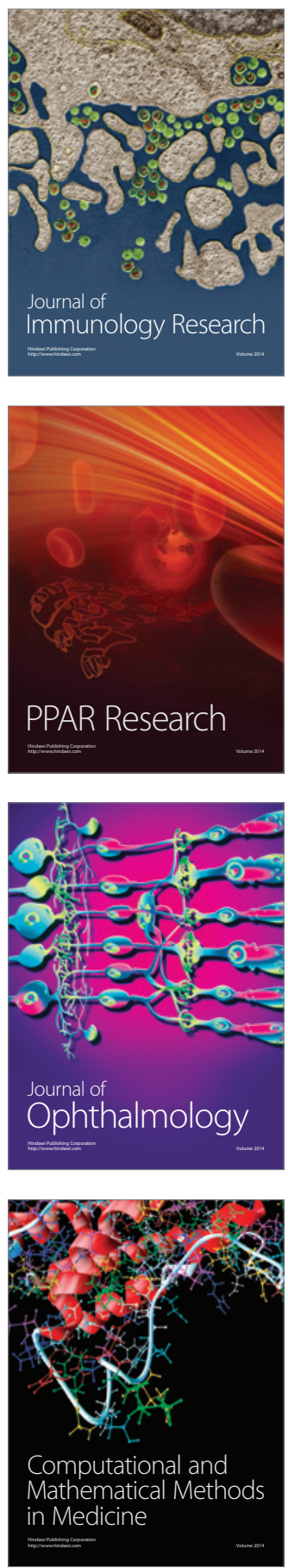

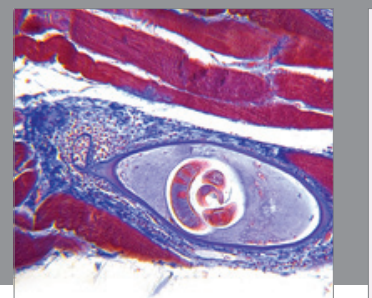

Gastroenterology

Research and Practice
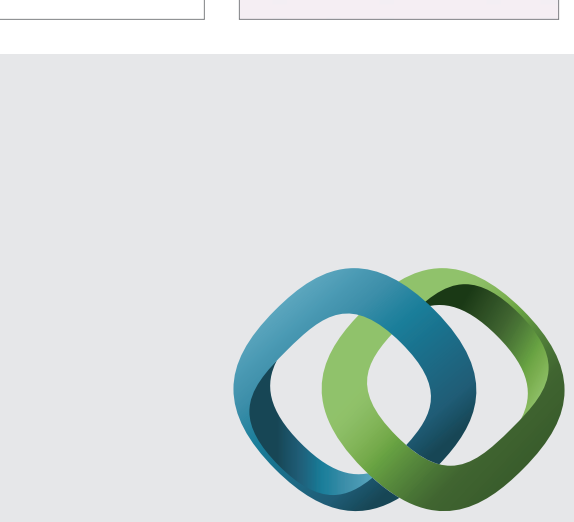

\section{Hindawi}

Submit your manuscripts at

http://www.hindawi.com
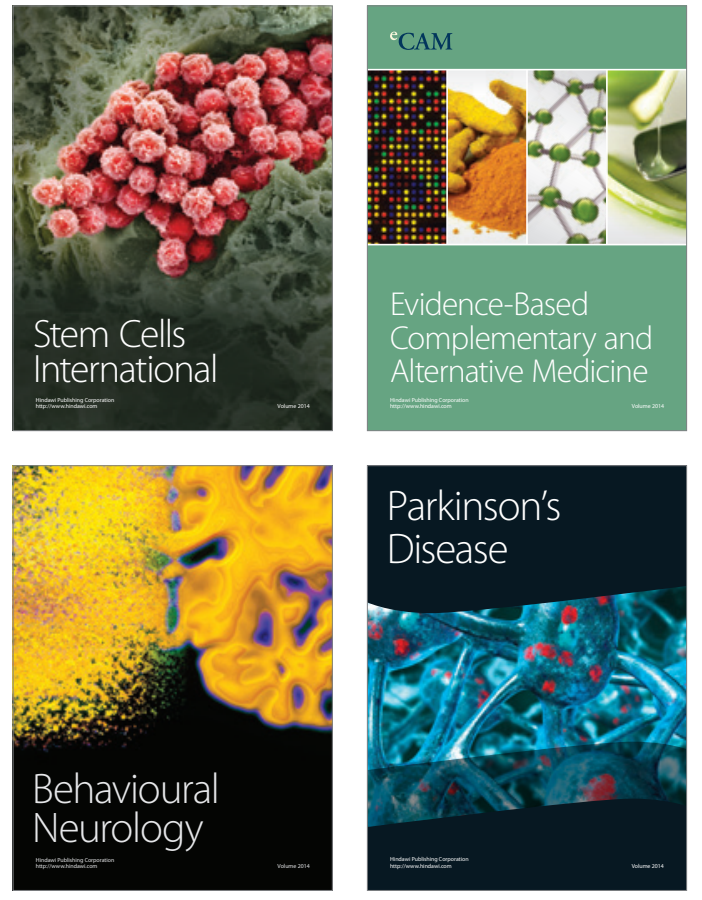
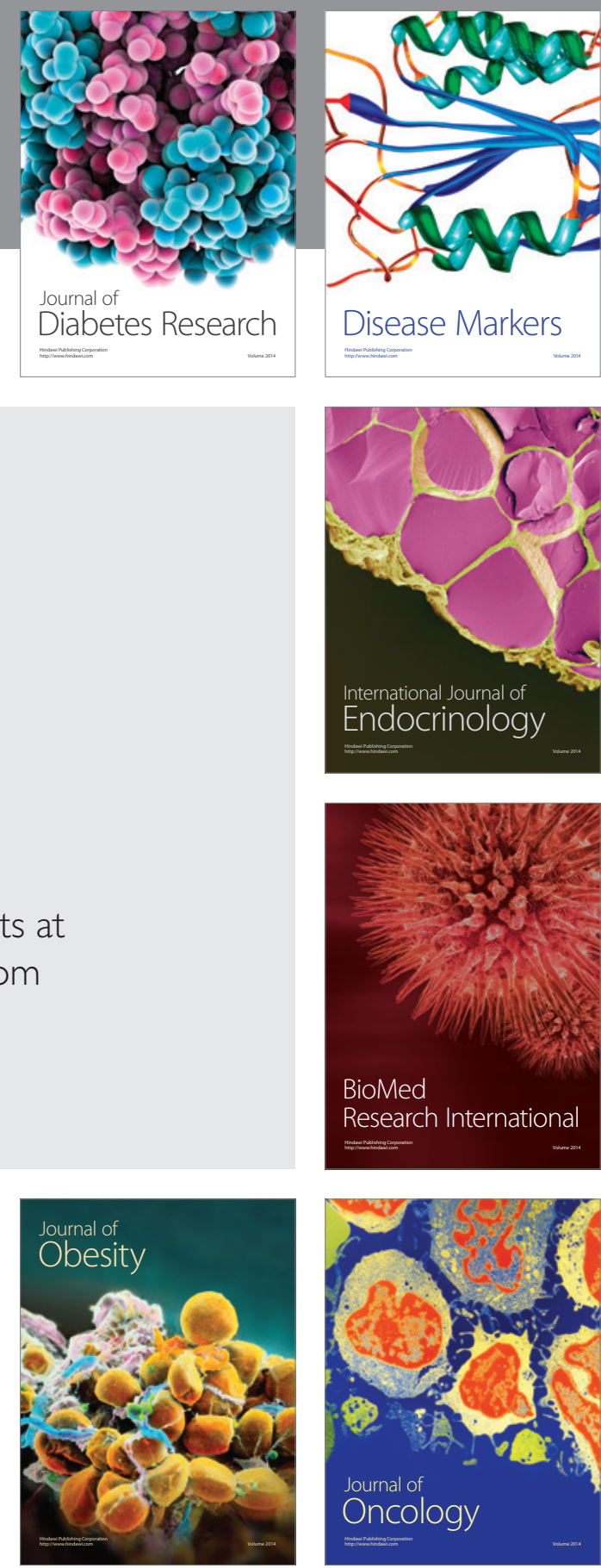

Disease Markers
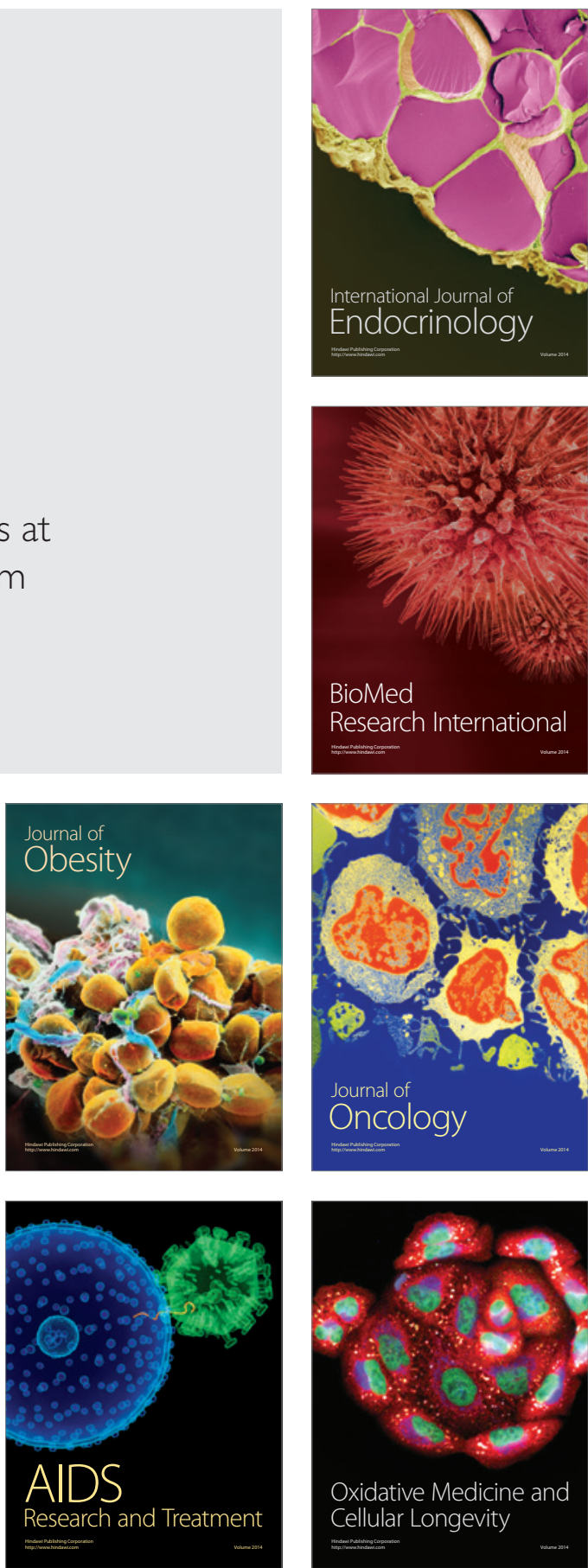